\title{
Competencias TIC de los Docentes para la Enseñanza Mediante Entornos Virtuales en Educación Superior. el Caso de la Universidad de los Andes-Venezuela
}

UT. Revista de Ciències de l'Educació Desembre 2014. Pag. 105-108 ISSN 1135-1438. EISSN 2385-4731 http://pedagogia.fcep.urv.cat/revistaut

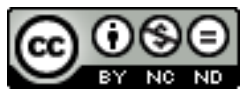

\section{Dayana Beatriz Carrillo Mejia ${ }^{a}$}

Data de defensa: 29/10/2014

\begin{abstract}
Palabras Clave: E-learning, Fisioterapia, Modelos instruccionales, Tecnología educativa, Voluntariado.
\end{abstract}

\section{Justificación y necesidades de la investigación}

Las perspectivas que las TIC presentan en el área educativa, exigen nuevos planteamientos que requiere un proceso de reflexión sobre el papel de la educación en un nuevo mundo vinculado por la comunicación a distancia. Se presentan diferentes escenarios para efectuar la enseñanza-aprendizaje marcado por una web con una dimensión más social y centrada en un entorno de trabajo colaborativo, de libre creación y difusión de contenidos, la construcción colectiva del conocimiento, así como, las necesidades de formación permanente en cualquier momento y lugar por medios tecnológicos. Todo esto marca la pauta para una urgente y acelerada transformación en las instituciones de educación universitaria y de sus modelos de enseñanza. Si no se concreta el cambio, la tendencia de estas instituciones será desaparecer del contexto educativo para dar paso a otras que satisfagan la demanda de personas que requieren utilizar efectivamente el conocimiento para su formación y empleo en un mundo competitivo e invadido por las TIC. Consciente de este panorama actual, la Universidad de Los Andes (ULA)-Venezuela se está encaminando para generar una transformación de manera apropiada, comenzado a utilizar la enseñanza virtual como complemento de la docencia tradicional, y también, para crear nuevas alternativas de estudio semipresencial, en un escenario donde el

\footnotetext{
${ }^{a}$ Profesora e investigadora de la Universidad de Los Andes (ULA). Trujillo - Venezuela.
} 
estudiante utiliza las TIC en su proceso de formación. Sin embargo, aunque se han realizado esfuerzos por introducir las mismas en el modelo pedagógico, algunas investigaciones realizadas en este contexto, resaltan la necesidad de formar a los docentes de esta institución para que puedan aplicar estas tecnologías de manera efectiva en la enseñanza-aprendizaje a través de Entornos Virtuales. Aún cuando las unidades académicas responsables de programas de capacitación docente de la ULA tales como, la Coordinación de Estudios Interactivos a Distancia (CEIDIS) y el Programa de Actualización Docente (PAD), han realizado grandes esfuerzos para mejorar la profesionalización del docente, apenas han tocado algunos elementos relacionados a estos nuevos modelos pedagógicos mediante el uso de las TIC. Este factor es parte de lo que justifica esta investigación, de la cual se obtiene una visión adaptada al contexto y a la realidad institucional que proporcionó las directrices para un diseño de un plan formativo orientado a desarrollar las competencias TIC que permitirá al profesor de la ULA desenvolverse de manera efectiva en estos espacios virtuales._ Por todo lo expuesto, esta investigación representa un importante aporte para esta institución universitaria, en el cambio de la cultura organizacional de su personal docente especialmente en materia de formación, y en las políticas, planes y proyectos institucionales que involucra al profesorado orientados desde el Vicerrectorado Académico de la ULA a través del PAD y CEIDIS. Esto contribuye con la necesaria transformación universitaria que le permita afrontar exitosamente los nuevos retos y modelos educativos originados por el auge de las tecnologías. En síntesis, los objetivos de la investigación se resumen en:

1. Evaluar los planes de formación en TIC que ha desarrollado la ULA en el periodo 2008-2013.

2. Identificar las necesidades de formación del profesorado de la ULA en competencias TIC para la enseñanza en entornos virtuales.

3. Diseñar un plan de formación en competencias TIC en entornos virtuales para el profesorado de la ULA

\section{Metodología}

Para lograr los objetivos se efectuó una investigación cualitativa multienfoque, donde se opta por un método de carácter mixto o multimétodo bajo el paradigma descriptivo-interpretativo ya que nos centramos dentro de un contexto educativo (Universidad de Los Andes-Venezuela), del cual tratamos de comprender la realidad formativa en TIC de sus profesores.

Aunque prevalece el diseño descriptivo (enfoque principal o dominante) se utilizaron métodos cualitativos mediante el análisis de contenido de algunos elementos. Se utilizó la triangulación de métodos y datos para obtener resultados más confiables y en algunos casos como complemento en el análisis.

En cuanto al diseño y proceso de recogida de datos se realizó en dos etapas: 
-Etapa1: aproximación al contexto de investigación. En esta se revisaron los planes de formación en TIC existentes que son ofertados por la Coordinación de Estudios Interactivos a Distancia (CEIDIS) y el Programa de Actualización Docente (PAD); obtuvimos las estadísticas del profesorado que ha sido formado a través de estos planes; se inició el acceso al entorno virtual de la ULA para verificar los profesores que hacen uso del entorno durante estos años; se logró crear una base de datos cruzada y completa de los principales datos del personal docente y de investigación, cuyos datos suministrados por las principales dependencias de la institución encargadas de administrarlos (Dirección de Asuntos profesorales, Red de datos de la ULA y la Dirección de Sistemas Informáticos Administrativos) y se revisaron otros documentos relacionados a solicitudes y planteamientos sobre los cursos de formación recibidos por CEIDIS.

-Etapa 2: recogida de datos, se diseñaron y aplicaron los siguientes instrumentos:

*Un cuestionario 1, para conocer el nivel de Competencia TIC del profesorado para la enseñanza en entornos virtuales en la Universidad de Los Andes.

*Un cuestionario2, para detectar necesidades formativas del profesorado de la ULA para la enseñanza en entornos virtuales.

*Una planilla para registrar datos de las observaciones del uso del entorno virtual de enseñanzaaprendizaje de la ULA por parte del profesorado que ha sido previamente formado en estos entornos virtuales.

\section{Población y muestra.}

Nuestra población comprende, por una parte, la población 1, el total de los profesores de la Universidad de Los Andes representada por un universo de 2627 profesores adscritos a las distintas dependencias universitarias (Facultades y Núcleos), por otra parte, en este estudio se tiene una población 2, constituida por el total de 778 profesores que ha recibido formación en CEIDIS en los últimos seis (06) años (2008-2013).

Con la población 1 , se obtuvo la muestra1 para aplicar el cuestionario 1 a través del cálculo probabilístico con un error máximo de estimación de 5\%. La muestra real está representada por 204 respuestas que se consideran representativas ya con este tamaño, el error estuvo cercano a la estimación establecida por el cálculo.

Con la población 2, se obtuvo la muestra 2 para aplicar el cuestionario 2 y aunque su tamaño se calculó probabilísticamente, este valor solo nos sirvió como una referencia debido a que la muestra se elige en función de un prototipo ("muestra homogénea"), donde todos los participantes tienen en común que han recibido formación del CEIDIS. En la muestra real seobtuvieron 59 respuestas. 


\section{Conclusiones relevantes}

-En términos generales, se puede decir que: el profesorado de la ULA, se encuentra en un nivel bajo a intermedio en todas las dimensiones de las competencias TIC, sin embargo, la mayoría del profesorado participante percibe positivamente las principales posibilidades o ventajas más significativas de las TIC en la enseñanzaaprendizaje, representando una fortaleza y buen punto de inicio para continuar avanzando en su formación y por consiguiente en un cambio organizacional.

-Para lograr con efectividad, una propuesta de plan formativo se establecen unos ejes de actuación que suponen puntos de atención importantes y robustecen dicha propuesta. Estos ejes se encuentran enfocados en:

a) elementos destacados del nivel de competencia del profesorado de la ULA;

b) Identificación de necesidades y otros elementos como mejoras planteadas, dificultades encontradas en el plan formativo vigente ofrecido por CEIDIS y c) otros hallazgos de la investigación; que han de contribuir a: (1) mejorar aspectos de la Competencia TIC del profesorado; (2) ampliar, perfeccionar y adaptar el plan formativo actual del CEIDIS a la realidad del contexto donde se implementa y (3) preparar a la institución para un cambio formativo de su profesorado y en consecuencia al cambio organizacional en materia tecnológica y de su modelo pedagógico.

-Se obtuvo un diseño curricular de cinco módulos organizados por distintos niveles que fortalecen las cinco dimensiones fundamentales de la competencia TIC del profesor: técnico o instrumental; pedagógico; social, ético y legal; desarrollo profesional y organización y gestión. Estos módulos constituyen un Plan de Formación en competencias TIC para la enseñanza en EVEA del profesorado de la ULA.

-Como aporte adicional de esta investigación, se plantea la integración del Plan de Formación en competencias TIC para la enseñanza en EVEA del profesorado de la ULA -obtenido como parte de los objetivos del esta tesis-, con el Programa de Actualización Docente ofrecido por PAD y un curso de alfabetización digital constituyendo una propuesta de mayor alcance, un Programa de Alfabetización y Desarrollo en TIC para el Personal Docente y de Investigación de la ULA. 